\title{
Community based intervention on adolescent risk taking: using research for community action
}

\author{
Carolyn Coggan, Barbara Disley, Pam Patterson
}

\begin{abstract}
Objectives-To use research on adolescent risk taking behaviour as an impetus for a community to develop locally based injury prevention strategies.

Design-Case study, based on a community action model and formative evaluation. This involved: a community profile on adolescent risk taking behaviour; interviews with service providers; dissemination of research findings to local policy makers; development and implementation of a community action plan to address adolescent risk taking; and assessment of its impact.
\end{abstract}

Setting-A rural town with a population of 10195 situated in the North Island of New Zealand.

Subjects-School aged adolescents and the safety policies and practices of community organisations involved with adolescents.

Results-Risk taking behaviours identified by the community profile included: drink-driving, substance abuse, carrying of weapons with intent to harm, and suicidal ideation. Community members identified that risk taking behaviour associated with alcohol in relation to: (1) violence (self directed and assault) and (2) road related injuries should be the focus of their activities. The strategies identified focused on advocacy, education, legal/regulatory change, and environmental modification. Evaluation conducted six months after intervention identified increased community awareness of the adverse effects of adolescent risk taking and some changes in policies and practice related to adolescent safety. Conclusions-Providing a community with local information that has high relevance for its members may act as a stimulus for the development of injury prevention initiatives. While this case study illustrated that a comprehensive approach focusing on adolescent risk taking behaviour, rather than on isolated injury problems, may be an appropriate way to highlight escalating adolescent injury rates, it also demonstrates the limitations of a short time frame for a community development project.

(Injury Prevention 1998;4:58-62)
Keywords: adolescent; risk taking; commnunity; formative evaluation

Internationally, and in New Zealand, injury is the leading cause of death among adolescents. ${ }^{1}$ Adolescence is also often a time when risks are taken. Activities such as not wearing bicycle or motorcycle helmets and seatbelts, drinkdriving, substance abuse, unprotected sexual intercourse, physical violence, and self mutilation, all have the potential to affect the health of young people and cause loss, concern, and costs to all levels of society. ${ }^{2}$ Recent reviews have shown that these high risk behaviours may be interrelated. ${ }^{3}$ It has also been suggested that a comprehensive approach that focuses on adolescent risk taking behaviour in general may provide a more effective injury prevention strategy than approaches targeted on specific injury problems. ${ }^{4}$ Providing local data to a community to increase their awareness of the need to develop strategies to prevent injury has been previously demonstrated. ${ }^{5}$ Very few, however, have focused exclusively on adolescents.

The community action model of research, which provided the framework for this work, is based on a number of assumptions that address both science and practice. ${ }^{6}$ From the perspective of research, studying adolescents in context is good science because these are the contexts in which adolescents live their lives. From the perspective of practice, local data are more applicable to that community and, as such, are more useful to local practitioners and policy makers (including parents who make policies in the home and influence community policies). In the language of social science, local community members often question the "external validity" of research conducted elsewhere. ${ }^{7}$ Furthermore, it has been shown that local residents are more likely to respond to programmes developed by members of their own community often in collaboration with outside researchers. ${ }^{8}$ This report describes the process of using research on adolescent risk taking behaviour to stimulate a community to develop locally based injury prevention strategies.

(1) Adolescent risk taking: a community action programme

This adolescent community action programme (ACAP) was conducted over an 18 month 
period between 1994 and 1995. The lead agencies were the Mental Health Foundation of New Zealand (MHF) and the Injury Prevention Research Centre (IPRC) based at the University of Auckland, New Zealand. Funding (equivalent to US $\$ 18000$ ) was provided by one of the four regional health authorities (North Health).

The criteria used to select a community were the need for the community: (i) to be located in the North Health region; (ii) to have a discrete geographical location; (iii) to have at least one secondary school; and (iv) to have a hospital within is boundaries. Riverdale (pseudonym), a rural town in the North Island of New Zealand, met the above criteria. It has a population of 10195 , with $15-19$ year olds comprising $8 \%$ of the total population. Of these young people, $25 \%$ identify themselves as Maori (indigenous people of New Zealand) and $1 \%$ as Pacific Islands people. The remainder are of European descent.

The target audience for the ACAP were service providers and policy makers (including parents) associated with adolescents in Riverdale. All service providers and key policy makers within the education, health, welfare, justice, religious, local government, and recreation sectors participated in varying degrees in the development and implementation of the ACAP. Participation of parents was limited to those who attended the meetings (less than $20 \%$ of those eligible). Only a few members of the business community actively participated.

\section{(2) Problem being addressed}

The impetus to undertake a demonstration community action project centred on adolescent risk taking was both national statistics, demonstrating that injury is the leading cause of death for adolescents, and growing evidence suggesting that there is an relationship between risk taking behaviours and adverse health outcomes during adolescence. ${ }^{3}$ However, as has been demonstrated previously, national data are often insufficient to motivate communities to do anything about the problems facing their young people. ${ }^{9}$ To address this, local data were collected and disseminated.

Four local data sources were used: (i) 1989-94 public hospital discharge data relating to motor vehicle crashes, suicide attempts, and assaults; (ii) a risk taking questionnaire completed by all Riverdale students 16 years and over; (iii) 16 focus group discussions held with those who had left school; and (iv) 36 key informant interviews held with service providers.

Riverdale public hospital discharge data indicated that, for selected intentional and unintentional injuries, rates were comparable with the rest of New Zealand. Analysis of the questionnaire confirmed that adolescents in Riverdale were engaging in high levels of risk taking behaviour.

(3) ACAP: development and implementation

The developmental phase of this programme involved: finalising the programme structure; formalising a relationship with the selected community; selection and training of two local programme coordinators; preparation of the risk taking profile; and dissemination of the findings. The implementation phase began with a community workshop facilitated by members of the two outside agencies. At this workshop, participants identified that risk taking behaviour associated with alcohol should be the focus of their activities. A group was established to implement the following strategies:

\section{(A) ADVOCACY}

- To support, on a local level, a ban on alcohol sponsorship of sport.

- To support stricter enforcement of underage drinking laws.

- To promote and encourage organisations providing conflict resolution strategies.

- To promote a wide range of recreational and leisure activities that do not centre on the consumption of alcohol or the taking of drugs.

- To identify, provide information on, and actively promote, referral of "at risk" adolescents to appropriate agencies.

\section{(B) EDUCATION}

- Support for the reintroduction of the school curriculum programme "Students Against Drink-Driving".

- Provide information to adolescents on the impact of alcohol and cannabis, and actively support initiatives to change the culture of their acceptance.

- Provide opportunities for adults to be made aware of the responsibilities they carry as role models, that is their need to better monitor their own drinking and drug use, as well as that of their own adolescent children.

- Provide extensive education for teachers at the local high school relating to the identification and referral of "at risk adolescents".

- Support the testing of a curriculum based programme "Mental Health Matters" being developed by the MHF.

\section{(C) LEGAL/REGULATORY CHANGE}

- Support changes to the law concerning alcohol and sports promotion; in particular, to support an alcohol tax for sports sponsorship similar to that of tobacco.

- Support stricter regulations surrounding the consumption of alcohol on sporting premises.

- Support stricter penalties for those who serve underage drinkers.

- Support regulations to restrict the carrying of weapons by adolescents.

\section{(D) ENVIRONMENTAL MODIFICATION}

- The provision of a multipurpose facility for adolescents.

- Support for the employment of a youth community worker.

- Support the employment of a specialist alcohol and drug counsellor. 
- Work towards developing stronger networking links so that leisure/recreational resources are more widely used to support initiatives for adolescents.

- Work towards providing more opportunities for the development of stronger networking between health, education, and justice professionals involved with adolescents.

The above strategies involved the local coordinators and members of the representative group working with and coordinating the appropriate agencies and monitoring their progress. The local coordinators were responsible to the representatives from the two outside agencies, and between the regular visits made by these representatives, kept in regular contact with them by phone.

\section{(4) Evaluation}

Formative evaluation is a means by which programme activities and progress are assessed. The primary aim of the formative evaluation was to develop strategies that would address adolescent risk taking and promote wellbeing. This was achieved through the provision of information relevant to programme development and implementation, and included: the adaptation of an effective community development model; acknowledging the restrictive nature of the time frame; reinforcing the value of interagency collaboration and the collaboration of community groups with outside agencies; identifying, obtaining, and presenting relevant information in a timely manner, conducting evaluation to assess impact of the ACAP; and highlighting issues that need to be addressed before the commencement of similar programmes in other communities. No attempt to determine effects on injury outcomes was undertaken.

Providing effective ongoing formative evaluation input required maintaining a critical perspective on the programme, while working closely with those involved in planning and implementing it. The fact that the formative evaluator had an independent institutional base assisted in maintaining a critical perspective. In an activity such as the ACAP, where the intervention is in an emerging or development phase, a critical role for formative evaluation is to help community members identify goals and develop strategies for achieving them. The activities undertaken as part of this ACAP emerged largely through the discussion and planning process at community meetings. The role of the evaluator at these meetings was to bring research based substantive knowledge of adolescent risk taking and injury prevention to assist the discussions.

It is difficult to accurately assess the impact of this evaluation on eventual programme outcomes. Assessing changes in adolescent risk taking behaviours and attributing these to the ACAP is problematic. This community action programme was not designed in such a way, and did not operate in a context that would allow clear conclusions to be drawn about its effects. However, evaluation conducted six months after the community activation workshop indicated that work had progressed to varying degrees on many of the strategies, especially those relating to environmental modification and education. For example, funding was provided for the employment of a specialist drug and alcohol counsellor for adolescents, premises were provided for a youth recreation centre, the curriculum based programme "Mental Health Matters" was tested at the local high school, teachers attended workshops to identify "at risk" adolescents, and the community had an opportunity to attend similar workshops. In addition, it was found that while the Maori community were not well represented in the development of the injury prevention strategies, representatives of this community were actively involved in this implementation.

\section{(5) Lessons learned}

Interagency support was an important impetus for the development of this locally based initiative. The comprehensive approach adopted by the MHF and IPRC, involving the community in the development of its own prevention strategies, resulted in the implementation of many initiatives to address risk taking behaviour. A key component was the employment of two community organisers. They acted as catalysts, helping adolescent risk taking issues to have a higher profile, and by encouraging institutions at the local level to take a greater role in injury prevention. The community adolescent health profile, especially the results from the adolescent risk taking survey, was a pivotal mechanism for community activation as well as the support given to the MHF and the IPRC by the local high school.

Unfortunately, the time frame for this project was short. A community development project needs sufficient time for all cultural groups to become involved. Initially, the Maori community were not well represented, but at the evaluation six months after the project Maori support for, and active involvement in, the implementation of injury prevention strategies was evident.

The conduct of this ACAP provided valuable insights into the process of community activation. It illustrated how providing a community with information can act as a stimulus for the development of injury prevention initiatives. It also suggests that using a comprehensive approach focusing on risk taking behaviour rather than on isolated unintentional or intentional injury problems may be an appropriate way to address escalating adolescent injury rates.

For additional information contact Dr Carolyn Coggan at the Injury Prevention Research Centre; phone +64 $93737999 \mathrm{x}$ 6348; fax +649 3737503; e-mail: c.coggan@auckland.ac.nz.

1 Public Health Commission. Our health our future. The state of public health in New Zealand. Wellington: Public Health Commission, 1994.

2 World Health Organisation. World health annual statistics. Geneva: WHO, 1994.

3 Hewitt N, Elliott B, Shanahan P. A review of risk behaviours among 15-24 year olds. Monograph Series No. 3. Canberra: 
Commonwealth Department of Human Services and Health, 1995

Rivara FP. Adolescent injuries: epidemiology and prevention [book review]. Inj Prev 1996;2:77-8.

5 Svanström L, Ekman R, Schelp L, et al. The Lidköping Accident Prevention Programme- a community approach to preventing childhood injures in Sweden. Inj Prev 1995;1: 169-72.

6 Rapoport RN. Research and action. In: Rapoport RN, ed. Children, youth and families: the action-research relationship. New York: Cambridge University Press, 1985: $1-25$.

7 Schorr LB. Within our reach: breaking the cycle of disadvantage. New York Anchor, 1989.

8 Small SA. Collaborative, community-based research on adolescents: using research for community change. fournal of Research on Adolescence 1996,6:9-22.

9 Jeffs D, Booth D, Calvert D. Local injury information community participation and injury reduction. Aust $\mathcal{F}$ Public Health 1993;17:365-72.

\title{
Children and personal watercraft: injury characteristics and potential countermeasures
}

\author{
Chester S Jones
}

Every summer, families and children travel to the waterways to participate in recreational activities. One increasingly popular water activity for children is riding on, or operating, personal watercraft (PWC). When these were first produced in the 1970 s, they were one seat water vessels with a maximum of 40 horsepower engines. Today, many manufacturers are producing vessels with three seats, horsepowers over 120-135, able to reach top speeds of 65-70 miles per hour. Although there are many variations, the most popular is known in America as a Sea-Doo.

These PWCs generally cost $\$ 4000$ to $\$ 8000$. As one PWC dealer stated, "You would have to spend at least $\$ 35000$ to $\$ 40000$ for a boat to go that fast. Personal watercraft is a cheap way to go fast". ${ }^{1}$ Clearly, PWCs are getting bigger and faster and manufacturers appear to be targeting younger populations through sophisticated media advertisements, splashy designs, and appealing to the inherent "fun" of PWC use.

In response to the possible dangers from their use by people 18 years and under, many states in the US have passed regulations governing their operation. But questions remain: how safe are PWCs? Are these countermeasures enough? Are those under 19 at greater risk for injury as operators or passengers than older users? Another concern is for the safety of other users of the waterways.

Indications are that injuries, disabilities, and fatalities are increasing as the popularity of these boats grows. Injuries from PWC related crashes in the US have more than doubled from 1990-94. ${ }^{2}$ Those to operators under 20 years of age have increased by $50 \%$ during the same time (these percentages do not include passengers). The magnitude of this public health problem, and research to prevent PWC related injuries, has not been adequately addressed. ${ }^{3-6}$ This may be due to the relatively recent emergence of the PWC as a popular watercraft or to the lack of detailed information or surveillance of incidents involving PWCs.

This paper describes childhood use and injury risk associated with PWCs in Arkansas, the availability and accuracy of injury data, and suggests areas for improved surveillance and countermeasures.

\section{Methods}

To document the use and describe injuries associated with PWCs, boating accident reports provided by the Arkansas State Game and Fish Commission from 1994 through July 1996 were collected. By state law, all boating accidents involving a fatality or $\$ 100$ or more in personal property damage must be reported to the commission. These reports are collected by boating accident investigators certified through the US Coast Guard. Before 1994, the reporting of such accidents was the sole responsibility of the individuals involved and it was likely the data were inconsistent and unreliable. Therefore, researchers did not compile reports collected before this date.

\section{Results}

Over a 30 month period, Arkansas waterways recorded 82 wrecks, 57 injuries, and four deaths involving PWC. In most cases the operator was responsible for the event. Operators under the age of 18 were involved in $43 \%$ (35) (mean age 14 years), less than 20 hours of experience $(69 \%)$, and most had no prior boating education class (98\%). Most passengers were also under the age of $18(70 \%)$. About half of all reported injuries occurred to those under the age of $19(48 \%)$. The youngest fatality was an 18 year old who drowned after being thrown from a PWC.

Of the 27 injuries to those under 19, four included the head and neck, four involved a lower extremity, and one an upper extremity; the body part was not specified in the remaining 18. Specific types of injury included fractures $(19 \%)$, lacerations $(11 \%)$, abrasions $(4 \%)$, sprain $(4 \%)$, drowning $(4 \%)$. Of the injured, $19(70 \%)$ were operators.

The most frequently cited causes for incidents involving operators under 19 were inexperience $(50 \%)$, inattention $(28 \%)$, and negligent operation (10\%). Alcohol was not noted as a factor in any report. Most events involved collisions between two vessels (77\%), 
with one out of five between two PWC. A majority occurred between June and July $(75 \%)$, on weekends ( $65 \%)$, and between $2 \mathrm{pm}$ and $6 \mathrm{pm}(57 \%)$.

Less than half of the victims under 19 reported they were swimmers (44\%), but most stated they were wearing a personal flotation device $(94 \%)$.

\section{Discussion}

This study has several limitations. The reliability of the data is uncertain due to the dependence on the accident investigator to record accurate, detailed information. Information to determine injury type, severity, and etiology is not required on the investigation form and therefore is minimal and inconsistent. Additionally, no data now exist that could provide information on the number of registered PWC in Arkansas. This would assist in determining mortality, incidence, prevalence, and risks.

However, even the limited results indicate clearly that PWC are involved in injury related crashes, and that children and young adults are a priority for prevention. Unfortunately, due to the PWC image as a toy, and the marketing tactics of manufacturers, children may be at higher risk for riding, operating, and therefore, for injury. As PWCs increase in use, size, speed, and there are more children operators, several strategies for prevention of injuries should be considered. Priority areas for possible countermeasures based on the findings of the study, are education, legislation or policy, and manufacturing, engineering, or design modifications.

\section{EDUCATION}

A large percentage of events arose from inexperience or inattention. Only one child had received any boating education. In the US, only 16 states require boating education and only 10 require special training for the operation of a PWC. ${ }^{7}$ The PWC is much different in handling, maneuvering, and other characteristics, than other boats. Mandatory PWC education and training programs for beginning operators could increase these skills and an appreciation for the responsibilities included in operating these boats.

\section{LEGISLATION}

At present, 43 states have age restrictions limiting PWC operators, but these vary from 10 to 16 years of age. ${ }^{7}$ Another six states require licensure for operation. Other regulations target speeding, restrictions on areas of PWC use, and boating environment policies. With regard to personal protection devices, most states require their use, but no state currently has laws pertaining to helmets. Due to the risk for head injury, helmets during PWC use should be considered.

\section{MANUFACTURING AND DESIGN}

As with any injury intervention, all this may not be enough. Just as with other products that have potential for injury, PWC manufacturers must take responsibility for developing safer vessels. In general, PWC are considered more safe than other outboard motorboats because their inboard propeller driven design decreases the risk for limb injury. But this is only one example of engineering design changes or modifications that could increase safety. Even though a majority of the wrecks on Arkansas waterways were attributed to human error, designing safer PWCs could limit those errors.

Enacting policies that limit age of PWC operation, mandating education and possibly licensure, and manufacturing design changes, are important countermeasures to consider.

These results are a call for injury professionals and researchers to (1) become more aware of PWC injuries in their communities; (2) enact better surveillance systems for characterizing the etiology of these events; (3) advocate for passage of age restrictions, education, and safe boating environment legislation; and, (4) require manufacturers to produce safer vessels by investing in the design of PWC that ensure safety as well as fun. Any interventions that have as their goal reducing injuries from PWC use should be evaluated for their effectiveness to determine the most appropriate strategies.

1 Whitman R. Personal watercraft get bigger. The Kansas City Star December 27 1996: D-8.

2 US Department of Transportation, United States Coast Guard. Boating statistics 1994. Washington, DC: US Department of Transportation, 1995. (Commandant publication P16754.8.)

3 Hamman BL, Miller FB, Fallat ME, et al. Injuries resulting from motorized personal watercraft. $\mathcal{f}$ Pediatr Surg 1993;28:920-2.

4 Vernberg D, Fine EG, Jagger J. Personal watercraft injuries. fAMA 1990;261:1883 [letter].

5 Francis RA, Vize R. Personal watercraft injuries: experience Francis RA, Vize R. Personal watercraft injuries: exp

6 Swinburn EE. Serious injuries in jet skiers. Med f Aust 1996;165:606-9.

7 Council of State Governments and National Association of State Boating Law Administrators. Reference guide to state boating laws. 1st Ed. Lexington, KY: Council of State Governments and National Association of State Boating Law Administrators, 1996. (Publication code C139-9600.) 